\title{
Dimensões temporais e espaciais da prática empreendedora em grupo: 0 caso da feira de artesãs como comunidade de prática
}

\author{
ARIANE LATOSKI ${ }^{1}$ \\ ELOY EROS DA SILVA NOGUEIRA ${ }^{1}$ \\ ${ }^{1}$ Universidade Positivo / Programa de doutorado em Administração, Curitiba - PR, Brasil
}

\begin{abstract}
Resumo
Este artigo propõe uma análise das dimensões temporais e espaciais da prática empreendedora em grupo e da sua aprendizagem, habilitação e capacitação para construí-las na estrutura social em que tal prática se situa. Para tanto, examinamos, sob a perspectiva da teoria social da aprendizagem, um empreendimento coletivo autogerido que precisa conquistar e construir seu lugar e momento com visibilidade, em termos simbólicos, econômicos e materiais, e enfrentar as condições adversas da estrutura social e a concorrência. No caso, escolhemos uma feira conduzida pelas próprias artesãs que oferece e vende os artesanatos delas ocupando espaço público e enfrentando a vizinhança de shopping centers. Adotamos uma metodologia qualitativa para estudo em profundidade. Concluímos que a territorialização pode ser uma atividade ou prática que define posicionamento e relações e, ao mesmo tempo que estabelece limites e fronteiras, cria conexões e novas possibilidades. Esse tipo de participação promove a aprendizagem do grupo - ou da comunidade - que o habilita a construir o espaço social e a estabelecer um lugar no contexto.
\end{abstract}

Palavras-chave: Comunidade de prática. Territorialização. Aprendizagem. Feira de artesanato.

Temporal and spatial dimensions of group entrepreneurship: the case of a craft fair as a community of practice

\section{Abstract}

This article proposes an analysis of the temporal and spatial dimensions of group entrepreneurship, covering aspects such as learning, qualification, and training to build the social structure dimensions around entrepreneurial practices. The study adopts the social learning theory to examine a self-managed collective enterprise working to gain space and momentum, expanding its visibility in symbolic, economic, and material terms, while facing adverse conditions of social structure and competition. The study analyzes a craft fair the artisans conduct themselves. The fair offers and sells handicrafts, occupying public space and facing the competition of shopping malls established in the same region. We adopted a qualitative methodology for in-depth study. We conclude that territorialization can be an activity or practice that defines positioning and relationships and, at the same time establishes limits and borders, creates connections and new possibilities. This type of participation promotes group or community learning, enabling the construction of social space and establishing a place for the fair in the context.

Keywords: Community of practice. Territorialization. Learning. Craft fair.

\section{Dimensiones temporales y espaciales de la práctica emprendedora en grupo: el caso de la feria de artesanas como comunidad de práctica}

\section{Resumen}

Este artículo propone un análisis de las dimensiones temporal y espacial de la práctica empresarial grupal y de su aprendizaje, calificación y formación para construirlas en la estructura social en la que se ubica dicha práctica. Para ello, examinamos, desde la perspectiva de la teoría del aprendizaje social, una empresa colectiva autogestionada que necesita conquistar y construir su lugar y momento con visibilidad, en términos simbólicos, económicos y materiales, y enfrentar las condiciones adversas de la estructura social y de la competencia. En este caso, optamos por una feria dirigida por las propias artesanas que ofrecen y venden sus artesanías, en un espacio público, en medio a los centros comerciales. Adoptamos una metodología cualitativa para un estudio en profundidad. Concluimos que la territorialización puede ser una actividad o práctica que define posicionamientos y relaciones y, al mismo tiempo que establece límites y fronteras, crea conexiones y nuevas posibilidades. Este tipo de participación promueve el aprendizaje del grupo -o de la comunidad-que le permite construir un espacio social y establecer un lugar en el contexto.

Palabras clave: Comunidad de práctica. Territorialización. Aprendizaje. Feria artesanal. 


\section{INTRODUÇÃO}

A noção de comunidade de prática tem recebido crescente atenção nos estudos de aprendizagem e conhecimento organizacional em território pátrio e as publicações refletem tal interesse e os esforços para estabelecer um plano conceitual básico (Ferrarini, Camargo \& Bulgacov, 2014; Mendes \& Urbina, 2015). Ela está associada à teoria da aprendizagem situada, que propõe que conhecimento e aprendizagem são alcançados com o agir em determinado contexto material e social (Brown \& Duguid, 1991; Lave, 2011; Lave \& Wenger, 1991; Wenger, 2011). Indo além, essa noção traz a perspectiva de que a aprendizagem se dá no contexto de nossa própria experiência de participação no mundo, um fenômeno de nossa natureza social. A participação, nessa aproximação, contempla as relações entre a estrutura social e a condição situada da experiência nas ações que a produzem e reproduzem (Giddens, 2003; Wenger, 2011). Nessas relações se dão as continuidades e descontinuidades, as possibilidades, as improvisações, as interações. Wenger (2011) busca uma conceituação mais precisa para a noção de comunidade de prática, pensando em identificar suas fronteiras e seus limites, aquilo que lhe é interno e externo, e sua localização e suas condições históricas. Em seu entendimento, a prática não cria somente limites, mas também constitui conexão. Sua geografia da prática sugere que a comunidade é um nível da estrutura social (Wenger, 2011) e que a aprendizagem é um motor de desenvolvimento da prática por seu caráter estruturador. Contudo, como apontam Fahy, Easterby-Smith e Lervik (2014) e Lervik, Fahy e Eastertby-Smith (2010), as dimensões temporal e espacial parecem ter recebido menos atenção nos estudos organizacionais, em especial naqueles dedicados à aprendizagem e conhecimento organizacional. Essas teorizações sobre prática descrevem o contexto como o continente em que a prática encontra seus elementos essenciais, como a estrutura social onde a prática tem seu sentido e significado e realiza o mundo social. Tempo e espaço são vistos, geralmente, como dados da realidade natural - parte do mundo - e as pessoas podem experimentá-los, mas não criá-los. Este artigo reflete a respeito sob um ponto de vista diferente: o de que podemos investigar tempo e espaço como constitutivos das relações e práticas sociais e, ainda, como por elas constituídos. Reflexões anteriores sobre isso (Bachelard, 1978; Bourdieu, 2013; Certeau, 2014; Giddens, 2003; Harvey, 2017; Lefebvre, 1974) suscitam que a habilidade de influir ou construir ordens espaço-temporais é uma forma de poder social. A prática e a comunidade têm limites e fronteiras; sua existência pressupõe um espaço e um tempo delineados, relacionados a outras práticas e comunidades. O território surge da ação sobre o tempo e o espaço (Harvey, 2017; Mendes \& Cavedon, 2015) e traz suas dimensões política, material e simbólica para configurar as relações e as posições com outros entes do contexto ou da estrutura social.

A territorialização, assim, faz parte da vida da comunidade de prática e pode ter implicações quanto à aprendizagem situada, tendo em vista seu caráter estruturador.

O propósito deste artigo é propor uma análise inicial da possibilidade de que a prática da comunidade requeira dedicação de energia e ação sobre o espaço e o tempo para diferir da estrutura social dominante. E, adicionalmente, explorar as implicações quanto à aprendizagem e à capacitação da comunidade, sob o olhar da teoria social da aprendizagem. Para tanto, escolhemos estudar uma feira de artesãs. A feira é uma atividade por meio da qual as artesãs utilizam espaço público. Portanto, tem-se a dimensão da aprendizagem do fazer artesanal aliada à da ação de criar e conquistar um lugar no seio do espaço social coletivo.

\section{REFERENCIAL TEÓRICO}

\section{Aprendizagem situada em grupo e comunidade de prática}

O conceito de comunidade de prática tem sido usado tanto para entender o desenvolvimento da aprendizagem quanto como ferramenta para promover a transferência e o compartilhamento de conhecimento (Nicolini, Scarbrough \& Gracheva, 2015).

Sob esse olhar, Wenger, Mcdermott e Snyder (2002) desenvolveram uma argumentação que possibilita analisar a aprendizagem social em grupos de trabalho onde há mudanças substantivas, em especial as tecnológicas, e cuja apreciação aplicada aos tempos atuais nos parece proporcionar questionamentos e contribuições sobre a ação e a competência empreendedora em grupo de contexto social sob intensa e acelerada transição por força da tecnologia.

Wenger et al. (2002) consideraram que cultivar as comunidades de prática em áreas estratégicas da empresa é uma maneira de gerenciar o conhecimento, de forma sistemática, pois a explosão da ciência e da tecnologia cria um paradoxo: ao mesmo tempo 
que a crescente complexidade do conhecimento requer maior especialização e colaboração, a meia-vida do conhecimento torna difícil acompanhar o rápido ritmo das mudanças.

Wenger et al. (2002) apresentam 3 elementos que proporcionam um modelo prático para orientar o desenvolvimento comunitário, quais sejam:

1. Domínio - o trabalho de negociar um domínio compartilhado é crítico para o desenvolvimento comunitário. Uma comunidade deve se perguntar: que tópicos e questões realmente a preocupam?

2. Comunidade - o elemento comunitário precisa de atenção, organização e educação. Que papéis as pessoas vão desempenhar?

3. Prática - qualquer comunidade com interações sustentadas desenvolverá algum tipo de prática ao longo do tempo. Que conhecimento irá compartilhar, desenvolver, documentar? Que tipos de atividades de aprendizagem irá organizar?

Além disso, procurando descrever a dinâmica que possibilita a existência de uma comunidade de prática, Wenger (1998) propôs que esses elementos estão presentes em 3 dimensões:

1. Repertório compartilhado;

2. Empreendimento negociado; e

3. Engajamento mútuo.

A Figura 1 representa esse entrelaçamento.

Figura 1

As 3 dimensões de uma comunidade de prática.

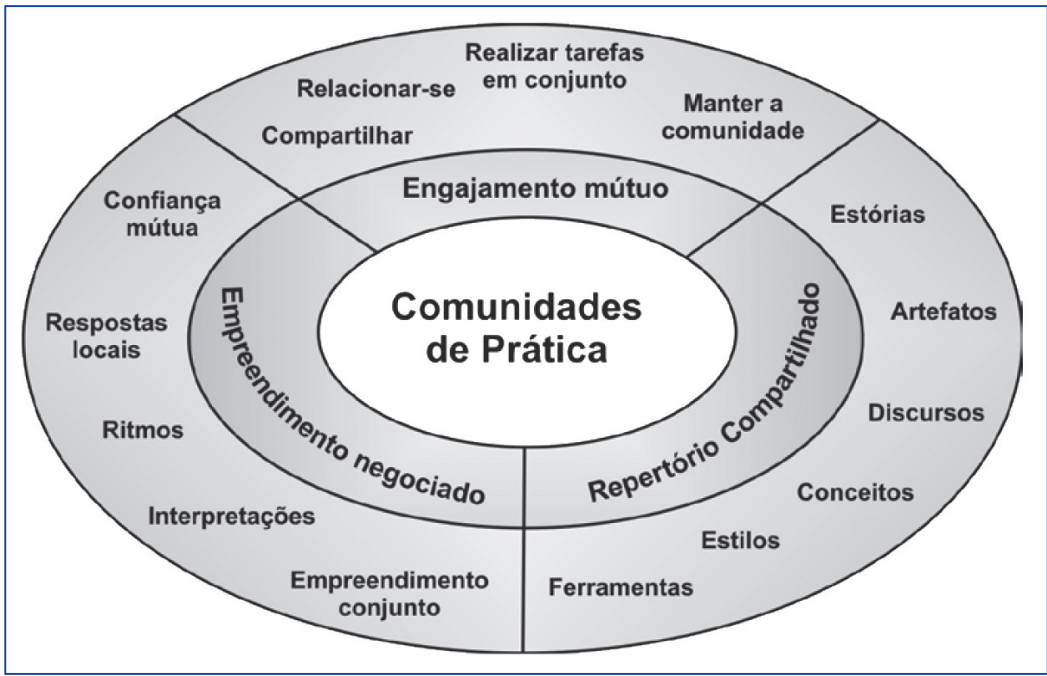

Fonte: Gouvêa, Paranhos e Motta (2008, p. 5).

Nas comunidades de prática, o senso comum, por meio do engajamento mútuo, elucida o caráter social e negociado entre o tácito e o explícito na vida das pessoas e no ambiente de trabalho. Esse sentimento de identidade e de pertencimento cria um ambiente facilitador de aprendizagem organizacional, no qual o conhecimento e a inovação ocorrem, segundo Gropp (2007), em estruturas informais da organização.

Lave e Wenger (1991) propõem que essa participação pode ser descrita a partir de uma posição inicial periférica e legitimada de onde parte uma trajetória de inclusão, ou seja, inclusão associada ao grau de conhecimento adquirido pela prática em um movimento rumo à plenitude por diferentes etapas de pertencimento ao grupo (Gropp, 2005).

Note-se que essas bases de teorização, recursivamente, concentram-se em uma prática que ocorre em ambiente organizacional e/ou em condições de trabalho. Os elementos postos como constituintes do processo de aprendizagem e da comunidade de práticas são consonantes com esse tipo de ambientes e condições. 
Entretanto, esta pesquisa se debruça sobre um empreendimento coletivo em que a feira é sua face mais visível, que se dá em espaço público. O trabalho artesanal não esgota o campo de conhecimentos que as feirantes devem dominar. Como grupo, suas ações devem sistematicamente (e não acidental ou eventualmente) se dirigir àqueles que dele não participam, em lugar e momento que precisam construir e delimitar, em determinado contexto.

\section{Espaço e tempo nas práticas sociais}

Os espaços (e seu tempo) são construções sociais complexas, baseadas nos valores e nos significados produzidos socialmente, em um modo dialético entre 3 aspectos: a) nas percepções e práticas cotidianas; b) nas representações e teorizações a respeito; e c) no imaginário espacial do tempo vivido. O espaço social coletivo está relacionado a uma prática espacial (Giddens, 1985, 2003; Hagerstrand, 1975; Lefebvre, 1974).

Bourdieu $(1997,2013)$ afirma que o espaço social se acha inscrito na objetividade das estruturas espaciais e simultaneamente nas estruturas subjetivas (esquemas de ação, pensamento e percepção). A distribuição de bens, relações e posições conjuga essas estruturas, suas significações e seus valores, em campos concorrentes, sobrepostos, contidos. O espaço físico traz inscritas as hierarquias definidas pelos espaços sociais. Essa é a realidade simbólica, revelada nos territórios e perpetuada pelas práticas sociais. Ocupar um espaço físico não implica usufruir do espaço social ou dele se apropriar de forma efetiva. Pode faltar ao neo-ocupante o tácito ou o hábito correspondente, que ele pode, contudo, buscar adquirir com o tempo.

Para Bachelard (1978), espaço e tempo são duas faces do devir histórico e dos esquemas de reprodução social: a materialidade cristaliza os significados que são atribuídos ao tempo.

Harvey (2017), por sua vez, propõe que os processos de reprodução e transformação da sociedade estão relacionados às concepções de espaço e tempo. E essas concepções são fundamentos para a manutenção do poder por meio desses processos sociais. Ele desenvolve um modelo para sua análise, 3 esferas dialeticamente inter-relacionadas em que se dá a prática espacial: a) fluxos e interações efetivos; b) representações contidas nos conceitos que conferem inteligibilidade (à espacialidade e à temporalidade); e c) negociações e reinterpretações de novos sentidos e representações para as práticas espaciais.

Essas esferas conjuminariam: a) os modos de significação e reprodução; b) os modos de apropriação e uso dos espaços; e c) os modos de domínio sobre as possibilidades de mudança em produção dos espaços.

Inspirados em Lefebvre (1974), Lervik et al. (2010) e Fahy et al. (2014) desenvolvem um quadro analítico que aproveita a concepção triádica do espaço (concebido, percebido e vivido) para estudar o espaço socialmente construído. Transpõem essa visão triádica dialética, ainda, para estudar o tempo (estruturas temporais concebidas, práticas temporais estabelecidas e experiência vivida dessas estruturas e práticas em determinados contextos e situações). E verificam como estruturas temporais influenciam e podem sincronizar as ações organizacionais e as interações entre seus membros e com outros e, ainda, como os atores podem delas se apropriar para o exercício de poder.

\section{Aprendizagem, territorialização, prática e cultura social}

Produzir artesanalmente subentende um fazer não industrial, em uma economia não escalar, na qual o artesão domina a tecnologia ou a técnica. Seu fazer imprime uma identidade pessoal e direta ao produto, mesmo quando se trata de um artesanato feito em grupo ou coletivamente.

Como sublinham Davel, Cavedon e Fischer (2012), o artesão incorpora, no seu fazer, senso estético, destreza física, domínio da técnica e competências de planejamento e de operação.

A visibilidade e invisibilidade do artista e artesão e de sua arte se relacionam com a dimensão do trabalho associado ao tempo-espaço social onde é desenvolvido (Chiesa, Gois, De Luca \& Cavedon, 2015) e, assim, pode ser valorado e eventualmente estigmatizado.

Ferreira, Helal e Paiva (2016), ao estudarem o caso das rendeiras de Alcaçuz-RN sob o olhar da teoria social da aprendizagem, demonstram como as artesãs adquiriram, dentro de uma comunidade (no caso a família), no cotidiano e na prática, sua competência e seu conhecimento tácito e, além disso, como seu fazer não se restringia ao domínio da técnica, mas dependia essencialmente de significados sociais compartilhados e associados à sua identidade e à construção de um lugar para si no espaço social. 
Carrieri, Pereira e Correia (2018) e Alves, Farias e Pereira (2018) analisam a prática de artesãos gastronômicos (no caso, pipoqueiros na mesma cidade), especialmente sua ação territorial, e demonstram, sob nosso ponto de vista, a importância do monitoramento mútuo entre eles para conduzir a ocupação e o uso do espaço público, antepondo ação ambulante e determinação de lugares e fronteiras, além de busca de poder e posições, seja por representatividade e associações, seja por negociações com terceiros, principalmente autoridades públicas.

Zioli, Rodrigues, Gaffuri e Ichikawa (2018) observam as práticas cotidianas não só concorrendo para reproduzir o espaço social, seus lugares e suas posições, mas demonstram as que criam rupturas e permitem divergentes territorializações, no caso um procedimento estratégico do movimento social que pretende, passo a passo, conquistar um lugar e uma posição, ainda que incerta, diante das reações do status quo. Resiliência e resistência combinadas com mudanças e não mudanças.

A resistência como prática que se dá no cotidiano, nos próprios modos de existência no espaço social comum e nas maneiras de fazer uso dele (Vasconcelos \& Domingues, 2018).

Para Haesbaert (2015), a territorialização é a apropriação do espaço na qual se destacam 3 dimensões, não necessariamente com importância idêntica entre si: a) a política; b) a simbólica; e c) a econômica. Ela tem natureza relacional e temporal, pois é resultante de processos sociais em espaço material.

Saquet (2015) também entende que a territorialização é espaço e tempo em movimento: relações sociais produzem território em temporalidades. Distintos conjuntos de relações sociais e temporalidades concorrem, convergem, superpõem-se e disputam espaço, caracterizando um múltiplo aspecto da dinâmica da territorialização.

Mendes e Cavedon $(2013,2014,2015)$ e Mendes (2011) enfatizam as dimensões cultural e econômica do comércio popular e informal (no caso estudado, um mercado de camelôs), cuja temporalidade e territorialização, por um lado, proporcionam sobrevivência e integração social aos intermediários e camelôs e, por outro, encontraram passo a passo, por meio das sucessivas instalações ao longo dos meses, um lugar (físico, econômico e simbólico) no espaço social local. A territorialização é a ação sobre tempo e espaço, é a construção social, com dimensões simbólica e política, em itinerários múltiplos, encontros e desencontros, vivências.

Pereira e Carrieri (2005), em marcante relatório que trata de movimentos de territorialização e desterritorialização, concluíram que o espaço simbólico, da territorialidade e da desterritorialização tem proximidade com os conceitos de organizações, práticas, identidade, significações culturais e relações de poder. Nos espaços simbólicos, como o território, há ambiguidade e aspectos relacionais que permitem adentrar os traços culturais.

A questão central não se limita a aprender um fazer, a ser reprodutor de uma prática, mas envolve o modo como o aprendiz pode tornar-se um prático, desenvolver uma identidade nesse universo de atividades espacial e temporalmente determinadas (Brown \& Duguid, 1991).

\section{METODOLOGIA}

A metodologia privilegiou observação, entrevista, diálogo e apreciação de fazeres, documentos e artefatos e buscou enfocar, descrever e acompanhar a vivência do grupo, as atividades e a constituição da prática, no cotidiano, de modo a identificá-las temporal e espacialmente. $E$, ainda, procurou-se descrever as condições de existência e conhecer os significados e a relações que representam. E também em incursões para observar, conhecer, descrever e mapear a geografia do espaço urbano e da vizinhança imediata em que se situa a feira, além dos outros lugares e tempos de atividades das artesãs (Gherardi, 2012; Nicolini, 2013; Stoddard, 2010; Van-Manen, 2007; Van-Maanen, 2009; Van-Maanen \& Barley, 1982; Van-Maanen \& Kolb, 1982).

A entrevista qualitativa possibilitou adentrar, mapear e compreender a vida dos respondentes, por meio de suas respectivas narrativas, que contêm crenças, valores, atitudes e motivações em relação a um contexto específico (Bauer \& Gaskell, 2002).

Para a entrevista narrativa, adotou-se a técnica de história de vida, com palavras e sentidos, específicos da própria experiência e do modo de vida. $\mathrm{O}$ acontecimento pode ser contado de forma concreta, em um lugar e tempo, para compor as narrações, que contêm experiências pessoais e formam um enredo (Bauer \& Gaskell, 2002; Josselson, 2011; Webster \& Mertova, 2007). 
O Quadro 1 ilustra o procedimento adotado na entrevista narrativa utilizada neste estudo.

Quadro 1

Fases principais da entrevista narrativa

\begin{tabular}{|l|l|}
\hline \multicolumn{1}{|c|}{ Fases } & \multicolumn{1}{c|}{ Regras } \\
\hline Preparação & $\begin{array}{l}\text { Exploração do campo } \\
\text { Formulação de questões }\end{array}$ \\
\hline 1. Iniciação & $\begin{array}{l}\text { Formulação do tópico inicial para narração } \\
\text { Emprego de auxílios visuais }\end{array}$ \\
\hline 2. Narração central & $\begin{array}{l}\text { Não interromper } \\
\text { Somente encorajamento não verbal para continuar a narração } \\
\text { Esperar para os sinais de finalização }\end{array}$ \\
\hline 3. Fase de perguntas & $\begin{array}{l}\text { Somente “O que aconteceu, então?" } \\
\text { Não dar opiniões ou fazer perguntas sobre atitudes } \\
\text { Não discutir sobre contradições } \\
\text { Não fazer perguntas do tipo “Por quê?" } \\
\text { Ir de perguntas exmanentes para imanentes }\end{array}$ \\
\hline 4. Fala conclusiva & $\begin{array}{l}\text { Parar de gravar } \\
\text { São permitidas perguntas do tipo "Por quê?" } \\
\text { Fazer anotações imediatamente depois da entrevista }\end{array}$ \\
\hline
\end{tabular}

Fonte: Adaptado de Jovchelovitch e Bauer (2002).

Os procedimentos para fazer a análise das histórias coletadas durante a entrevista narrativa são 3: a) a análise temática (conversão dos dados por meio da transcrição das entrevistas gravadas); b) a proposta do próprio Schultze (2010), de 6 passos (primeiro, a transcrição detalhada do material verbal; segundo, a diferenciação entre material indexado e não indexado; terceiro, o uso do material indexado para ordenar os acontecimentos; quarto, as dimensões não indexadas do texto são investigadas como análise do conhecimento, ou seja, opiniões e reflexões; quinto, o agrupamento e a comparação das trajetórias individuais; e sexto, a identificação de trajetórias coletivas); e c) a análise estruturalista (elementos formais da narrativa) (Jovchelovitch \& Bauer, 2002).

Outros instrumentos também foram utilizados na pesquisa de campo, como a observação participante e a análise documental.

Quadro 2

Descrição do procedimento de pesquisa

\begin{tabular}{|l|l|}
\hline $\begin{array}{l}\text { Número de horas } \\
\text { (Evento, observação de campo, } \\
\text { participação em reunião) }\end{array}$ & 70 horas \\
\hline Quantidade de entrevistas & 15 \\
\hline Documentos analisados & $\begin{array}{l}\text { Lei Municipal n. 14.786, de 23 de fevereiro de 2016, de Curitiba-PR } \\
\text { Regimento da Feira Economia Solidária do Portão }\end{array}$ \\
\hline Observação e participação & $\begin{array}{l}\text { Reunião da feira na Tecsol - Incubadora de Economia Solidária da } \\
\text { Universidade Tecnológica Federal do Paraná (UTFPR), Curitiba-PR } \\
\text { Montagem e desmontagem da feira } \\
\text { Mostra de Economia Solidária na UTFPR }\end{array}$ \\
\hline Material coletado & $\begin{array}{l}\text { Fotos } \\
\text { Folders }\end{array}$ \\
\hline
\end{tabular}

Fonte: Elaborado pelos autores. 
As artesãs foram identificadas por codificações que representam as letras iniciais de seus nomes: A.M., E.D.1; E.D. 2; M.A. 1; M.A. 2; N.A.; P.A.; S.I. (favor ver quadro 3 a seguir).

Cada entrevista foi transcrita e recebeu numeração que a localiza na sequência do conjunto. Assim, ela passou a compor o acervo dos dados. Os trechos das entrevistas apresentadas neste artigo trazem a codificação que identifica a qual delas se refere e em que linhas do texto transcrito. Por exemplo: E 1, 2-3 - entrevista número 1, linhas 2 e 3. E 10, 12-14 - entrevista número 10 (dez), linhas 12 a 14.

Foram aproximadamente 6 meses de imersão no caso (julho a dezembro). A observação e a participação se deram em reuniões de trabalho das artesãs, acompanhando-as em seu deslocamento, suas pesquisas e seus projetos de produção e em dias inteiros na própria feira (desde antes da montagem da infraestrutura até o final do dia, quando da desmontagem e guarda dos apetrechos e produtos). As notas de campo compuseram um diário a partir do qual foi possível elaborar descrições. Os diálogos e as entrevistas foram transcritos e viabilizaram a análise qualitativa de conteúdo, que embasou a identificação de temas e conteúdos de vivências do grupo e do empreendimento.

\section{APRESENTAÇÃO DOS DADOS E DISCUSSÃO}

\section{Descrição geral das atividades: localização, posicionamento e territorialização}

As mulheres chegam com antecedência para fazer a montagem das barracas. Conforme vão chegando, se concentram no espaço destinado à montagem de barracas e ficam aguardando o estacionamento abrir para pegar as carretinhas da feira, nas quais se encontram as estruturas para montar as barracas, as cadeiras, as mesas, as lonas de plástico, as saias de proteção das barracas e as barracas portáteis. Nesse movimento já há uma divisão de tarefas, de acordo com as possibilidades físicas e de saúde das feirantes. Algumas não conseguem carregar peso, então, ficam preparando e embalando as mercadorias, que, serão expostas na feira.

Todas montam juntas as estruturas das barracas; somente após todas estas estarem montadas tem início a etapa de arrumação de cada barraca - que deve ter 3 feirantes, no mínimo. Nesse momento, cada feirante faz, a seu modo, a arrumação do próprio espaço de trabalho, verificando a disposição dos produtos, a visibilidade dos preços, a exposição das novidades, a produção dos cartazes, enfim, cada uma faz a seu modo.

\section{[...] Todas montam e desmontam juntas as barracas (E 2, 2-3).}

Elas ainda não detêm os requisitos de legalidade, e sentem a dificuldade dessa situação. Entretanto, mostram-se preocupadas e articulam-se para mudar seu status jurídico. A cada dia de feira, não conseguem evitar o fato de que têm de lutar com a diferença marcada pela concepção da economia solidária em comparação ao comércio grandioso dos shoppings vizinhos, além de lidar com o desconhecimento dos passantes quanto à economia popular.

[...] Chega cliente e pede refrigerante, aí a gente explica que é uma feira de economia solidária, não trabalha com rótulo, a produção é própria (E 3, 5-6).

[...] Nós conseguimos vencer, há quase dois anos, somos protagonistas do nosso espaço (E 7, 3-4).

[...] Nós avançamos, fomos atrás de contador, informações, papéis, cartório e [estamos] quase finalizando a legalização da nossa feira (E 5, 10-11; e E9, 7-9).

As observações no cotidiano do evento e os testemunhos das entrevistas convergem para demonstrar que as artesãs veem no empreendimento uma missão e um modo de posicionarem-se proativamente na sociedade. Esses são elementos descritivos de seu sentido de existência, que elas reconhecem que foi construído, significado e tornado real em suas vidas nesses embates do dia a dia, para garantir sua sobrevivência, entre elas e com os visitantes e passantes, com vistas a superar a indiferença destes.

[...] Eu conto a história do meu produto, busco novidades e peço às amigas que viajam para trazer sementes diferentes para o artesanato (E 3, 13-14). 
Elas cumprem religiosamente o projeto de manter a feira funcionando durante 2 dias inteiros por semana, faça sol ou faça chuva. Sempre estão atentas às condições de suas companheiras e prontas para auxiliá-las quando necessário. Mas não é só isso. Mostram, ainda, uma atitude gentil e acolhedora para com os visitantes, que não são vistos como potenciais compradores, mas como seus "alunos" ou "filhos", com quem compartilham o que julgam ter de mais precioso.

[...] Veio uma menina de 9 anos, ela disse que tinha um trabalho de escola e eu contei a história do filtro de sonho. Ela tirou 10 (E 3, 16-17).

A maior parte das feirantes encontra-se na faixa etária de 55 a 60 anos, com idade média de 53 anos, e apenas $30 \%$ são novatas. A maioria está há mais de 2 anos na feira. Ou seja, são mulheres maduras que fazem um empreendimento solidário e trocam experiências com as mais novas, que reúnem e mobilizam as feirantes para reuniões, dividindo experiências de vida e de economia solidária.

\section{[...] Nós temos um regimento com princípios da economia solidária e da feira (E 5, 6-7).}

[...] Eu ajudo na administração, faço o livro-caixa. Para arrecadar fundos, fazemos bazar e clubes de troca (E 1, 9-10).

[...] Toda quarta-feira, antes de abrir a feira para o público, fazemos um café comunitário, uma oração, para começar bem o dia (E 1, 4-5).

\section{A feira como organizing, um conjunto complexo de atividades coordenadas entre si}

A feira, como prática, não se circunscreve no momento em que está posicionada no espaço público, com barracas montadas e atividades de exposição e comercialização. A feira, como evento, demanda uma série de outras atividades que a antecedem e outras que a sucedem, todas necessárias e concorrendo para o sucesso e a qualidade do evento.

[...] Todo mundo da feira tem que produzir seu produto. Essa é regra da economia solidária. Se não tenho produto, meu grupo arruma para eu vender. Cada feirante representa um empreendimento com no mínimo 3 pessoas (E 13, 3-5).

O trabalho da feira se estende para tempos e lugares diferentes, além de demandar maior dedicação das artesãs. Tal referência diz respeito a compras de insumos e matérias-primas, tarefas de preparação e processamento dos produtos, tarefas de pesquisa e estudo de materiais e técnicas etc. Esta pesquisa identificou e mapeou a extensão de tais atividades e das condições de autogestão, que conduzem e coordenam a realização desse processo e o integram, para viabilizar a experiência dessas artesãs como grupo em ação, dotado de propósito e capacidades dinâmicas. A esse respeito, de acordo com Gropp e Tavares (2007), destacam-se os seguintes aspectos:

- A divisão do tempo e as temporalidades se dão de duas formas: uma direta - nos momentos que estão juntas - e outra indireta - naquilo que se refere aos projetos e às atividades realizadas em outros momentos e lugares que não a feira como evento;

- Há conhecimentos especializados que se complementam para que o empreendimento se concretize; e, ainda, as atividades: de comercialização, instalação e gestão da feira como evento, de planejamento de atividades comuns associativas;

- Além de seu sentido de existência, a situação social e a identidade encontram na autogestão associativa o elemento que as distingue dos outros, no caso, a forma de fazer a feira, ou seja, por meio de montagem coletiva, pela compreensão da forma e do momento em que se contribui com o fundo, o que ocorre somente quando há comercialização, a forma de conduzir as reuniões, por meio de pautas, espaço para dar opiniões e votação sobre os assuntos apresentados.

Também se destaca que há temporalidades concorrentes relativas a diversas atividades, tais como aquelas de pesquisa, de projeto, de preparo das condições de produção e de produção propriamente dita. Esses tempos dependem das características da técnica artesanal, do produto e do perfil e das condições de trabalho da própria artesã. Além disso, há o tempo de preparo pessoal da feirante, seu deslocamento, a arrumação da barraca e a permanência no espaço público.

O Quadro 3 correlaciona as atividades que envolvem a prática com os lugares (espaços) e tempos disponibilizados para tal. 


\section{Quadro 3}

Atividades da prática da feira

\begin{tabular}{|c|c|c|c|c|c|c|c|}
\hline Dias da semana & Segunda-feira & Terça-feira & Quarta-feira & Quinta-feira & Sexta-feira & Sábado & Domingo \\
\hline Feirante N. A. & $\begin{array}{l}\text { R. F. ECOSOL- } \\
4 \text { horas } \\
\text { R. F. }-4 \text { horas }\end{array}$ & P- 7 horas & $\begin{array}{l}\text { F- } 9 \text { horas } \\
\text { P- } 5 \text { horas }\end{array}$ & $\begin{array}{l}\text { P- } 7 \text { horas } \\
\text { P. I- } 2 \text { horas } \\
\text { T. E. A. P- } 2 \text { horas }\end{array}$ & $\begin{array}{l}\text { P. } 5 \text { horas } \\
\text { C. M.- } 3 \text { horas }\end{array}$ & $\begin{array}{l}\text { F- } 9 \text { horas } \\
\text { P- } 5 \text { horas }\end{array}$ & P- 7 horas \\
\hline Feirante P. A. & $\begin{array}{l}\text { R. F. ECOSOL- } \\
4 \text { horas } \\
\text { R. F. } 4 \text { horas; } \\
\text { C. M.- } 2 \text { horas }\end{array}$ & $\begin{array}{l}\text { P. } 1-2 \text { horas } \\
\text { P- } 6 \text { horas }\end{array}$ & F-9 horas & P- 6 horas & P- 6 horas & P- 6 horas & P- 6 horas \\
\hline $\begin{array}{l}\text { Feirante M. } \\
\text { A. } 1\end{array}$ & $\begin{array}{l}\text { R. F. ECOSOL- } \\
4 \text { horas } \\
\text { R. F. } 4 \text { horas } \\
\text { C. M.- } 2 \text { horas }\end{array}$ & $\begin{array}{l}\text { P- } 5 \text { horas } \\
\text { C. M.- } 2 \\
\text { horas }\end{array}$ & F- 9 horas & $\begin{array}{l}\text { P- } 5 \text { horas } \\
\text { P. I- } 3 \text { horas }\end{array}$ & P- 5 horas & P- 5 horas & P- 5 horas \\
\hline $\begin{array}{l}\text { Feirante M. } \\
\text { A. } 2\end{array}$ & $\begin{array}{l}\text { R. F. ECOSOL- } \\
4 \text { horas } \\
\text { R. F. }-4 \text { horas } \\
\text { C. M.- } 2 \text { horas }\end{array}$ & P- 5 horas & F- 9 horas & $\begin{array}{l}\text { P. } 5 \text { horas } \\
\text { R. G. P. }-3 \text { horas }\end{array}$ & P- 5 horas & F-9 horas & $\begin{array}{l}\text { P. M. P. - } 4 \text { horas } \\
\text { [G. P. C. - } 4 \text { horas, } \\
\text { sendo } 1 \text { vez ao } \\
\text { mês] }\end{array}$ \\
\hline Feirante S. I & $\begin{array}{l}\text { R. F. ECOSOL- } \\
4 \text { horas } \\
\text { R. F. } 4 \text { horas; } \\
\text { C. M.- } 3 \text { horas }\end{array}$ & P- 4 horas & F-9 horas & C. M.- 3 horas & P- 4 horas & F- 9 horas & $\begin{array}{l}\text { C. F. F. }-2 \text { horas } \\
\text { C. F. Fs. }-1 \text { hora }\end{array}$ \\
\hline $\begin{array}{l}\text { Feirante } \\
\text { E. D. } 2\end{array}$ & $\begin{array}{l}\text { R. F. ECOSOL- } \\
4 \text { horas } \\
\text { R. F.- } 4 \text { horas; } \\
\text { C. M.- } 2 \text { horas }\end{array}$ & $\begin{array}{l}\text { P. M. P.- } 4 \\
\text { horas } \\
\text { P- } 6 \text { horas } \\
\text { P. I- } 1 \text { hora }\end{array}$ & $\begin{array}{l}\text { P. M. P.- } 4 \\
\text { horas } \\
\text { P- } 6 \text { horas } \\
\text { P. I- } 1 \text { hora }\end{array}$ & P- 10 horas & P- 10 horas & F- 9 horas & P- 5 horas \\
\hline $\begin{array}{l}\text { Feirante } \\
\text { A. M. }\end{array}$ & $\begin{array}{l}\text { R. F. ECOSOL- } \\
4 \text { horas } \\
\text { R. F. }-4 \text { horas }\end{array}$ & P- 5 horas & $\begin{array}{l}\text { P- } 5 \text { horas } \\
\text { R. G. P.- } 3 \\
\text { horas }\end{array}$ & P- 5 horas & C. M.- 3 horas & $\begin{array}{l}\text { F- } 9 \text { horas } \\
\text { P. I. R.- } 1 \\
\text { hora }\end{array}$ & P. I- 1 hora \\
\hline $\begin{array}{l}\text { Feirante } \\
\text { E. D. } 1\end{array}$ & $\begin{array}{l}\text { R. F. ECOSOL- } \\
4 \text { horas } \\
\text { R. F. } 4 \text { horas } \\
\text { P. } 3 \text { horas }\end{array}$ & $\begin{array}{l}\text { C. M. }-3 \\
\text { horas } \\
\text { P- } 5 \text { horas }\end{array}$ & F- 8 horas & P- 5 horas & P- 5 horas & F- 9 horas & \\
\hline
\end{tabular}

Legenda:

C. F. F. - Controle financeiro da feira

C. F. Fs. - Controle de frequência dos feirantes

C. M. - Compra de mercadoria, matéria-prima

F - Feira

G. P. C. - Grupo produz coletivamente

$\mathrm{P}$ - Produção

P. I. - Pesquisa para inovar os produtos na internet

P. I. R. - Pesquisa de inovação em revistas

P. M. P. - Prepara material para produzir

R. F. ECOSOL - Reunião do Fórum de Economia Solidária

R. F. - Reunião da feira

R. G. P. - Reunião do grupo de produção

T. E. - Troca de experiências de artesanato e produtos

Fonte: Elaborado pelos autores. 
Demonstra-se que as feirantes, em sua maioria, trabalham diariamente com as atividades vinculadas à feira, seja por meio do processo de produção, da participação em reuniões, da pesquisa de inovações nos produtos, da compra de materiais, de formações e eventos em universidades, conforme a demanda. Em média, dedicam-se 36 horas à feira. Diante do exposto, verifica-se que não há apenas o tempo de disponibilidade para a feira propriamente dita, ou seja, existe uma conjunção de atividades correlacionadas, que se estendem a outros ambientes, com um número de horas despendidas, além de outro número de horas não concernentes à atividade de feirante.

As feirantes produzem diariamente, com vistas a ter uma variedade de produtos e a aumentar sua probabilidade de comercialização. Quando há poucos produtos, a feira não se mostra atrativa para o cliente, que sempre busca opções de cores, modelos, tamanhos e formatos.

\section{[...] Lancei um produto de bolsinha com trocador, lenço e pomada. Vou começar a linha de bolsas para academia e futebol (E 4, 6-7).}

[...] Chega cliente e fala tem tal desenho, ai me passam por Whats[App] o desenho e transformo para bordar. Lancei bordado em toalha de Festa Junina (E 8, 12-13).

\section{[...] Às vezes falta dinheiro para comprar material. Aí tem que procurar material que substitua, a gente} conversa e pesquisa (E 5, 9-10).

O descanso envolve atividade correlata à feira, seja no momento em que se está na internet, pesquisando materiais ou tipos de pontos; ou quando se está viajando, e no caminho se vai bordando; e quando se está na praia também há produção, o que as artesãs consideram como uma terapia.

Não há um calendário definido de produção de festividade; cada barraca, junto com seu grupo, decide o que irá produzir, mas nem por isso se deixa de estar atentas ao calendário comercial.

\section{RESULTADOS E AVALIAÇÃO}

Essas artesãs trabalham individual e coletivamente nesse empreendimento. São ao mesmo tempo suas operárias e suas responsáveis; elas conduzem o trabalho em processo de autogestão e revelam solidariedade entre si e atenção para com seus clientes. Evidenciou-se haver um desafio adicional para essas artesãs, pois precisam trabalhar durante os outros 5 dias da semana para conseguir manter a feira por 2 dias inteiros na semana (quarta-feira e sábado) e, ao mesmo tempo, cuidar pessoal e diretamente de suas famílias.

A feira não se dá automaticamente ou em decorrência da repetição dos mesmos procedimentos. Sua existência flui de modo dinâmico, pois, além das artesãs cultivarem a atitude de buscar a inovação, elas têm de lidar com o inesperado e a concorrência (de ofertas de produtos, de ideias e de estratégias de comunicação para despertar o interesse e a atenção de consumidores). Ou seja, há elementos para a aprendizagem do grupo a partir de razões internas e, também, com base em razões externas a ele. $\mathrm{O}$ grupo se mostra estável e a entrada de novos membros ocorre somente após um cuidadoso processo de admissão por parte das artesãs. Há diferentes formas de participação para descrever sua aprendizagem, mas uma característica importante reside na mutualidade, que acompanha o fluxo de suas atividades paralelas e conjuntas. $E$ isso se constata em sua participação no processo de planejamento, de produção e de venda. Elas compõem uma comunidade de prática, pois estão engajadas, desenvolvem e mantêm cotidianamente um empreendimento, que reconstrói um repertório comum (haurido a partir de sua vivência e experiência em grupo, mas inspirado na economia popular). Elas delimitam as regras que conduzem seu funcionamento e seu processo de decisão. A produção é realizada por empreendimento, que sempre é coletivo.

Nesse sentido, mostra-se presente o pertencimento e a diferenciação. Há algo que acontece quando elas estão juntas, em termos de aprendizagem, conhecimento, estruturação de fazeres. Observa-se companheirismo entre as feirantes que se traduz em gestos, atitudes, fazeres, tais como, quando necessário: cuida-se da barraca de outra feirante; indica-se a barraca de outra feirante para encontrar determinado produto; conversa-se com aquela feirante que parece estar muito quieta. Todos esses gestos denotam laços que fortalecem as relações afetivas e a amizade.

Entretanto, existem regras de convivência e há forte sentimento e compromisso comum, pois, independente de cada artesã e cada barraca representar em si um empreendimento menor, a feira como um todo constitui um empreendimento maior, que envolve a todas e as une. 
Entre as feirantes há um modo de comercializar próprio, no contexto histórico e cultural em que elas estão situadas - mais um elemento que diferencia essa feira das outras.

Elas se referem a si mesmas como artífices praticantes da economia solidária e assim se identificam.

Ao transpor a feira para um espaço simbólico, verifica-se que isso abarca outros conceitos, como: a) as atividades que desenvolvem para constituir sua própria prática; b) a identidade que adotam quando mencionam "somos uma feira de economia solidária"; c) os aspectos relacionais que desenvolvem com aqueles que estão ligados direta e indiretamente com a feira; e d) as relações de poder que devem pôr em prática diante do público externo, abrangendo desde os fatores legais até o sistema de comercialização, além da interação com o público interno, por meio das regras estabelecidas.

Por intermédio do conceito de território, pode-se adentrar a história dos atores sociais quanto à organização, porque a feira é considerada como algo tão precioso, meio que colabora, inclusive, para a saúde psíquica e física das artesãs. Isso retrata os processos de identificação e a inscrição da história pessoal na organização.

A territorialização faz parte da comunidade e, ainda, do processo de aprendizagem. O relacionamento que feirantes desenvolvem com terceiros, como policiais, estudantes, passantes e moradores de rua, estende-se e envolve os outros personagens na territorialização da feira. Algumas feirantes relatam que certos clientes passam na feira e falam sobre as tendências da moda, dando sugestões de produtos, e também ocorre troca de experiências entre artesãos que circulam no local.

Entretanto, as observações e o conteúdo dos relatos da experiência das artesãs confirmam e reconhecem o poder e a influência da vizinhança dos shopping centers. Estes definem determinada organização espacial e social que cria uma realidade e impõe um processo de socialização para seus usuários, como sugeriram Lengler e Cavedon (2018). Apesar de serem espaços privados criados para o uso da coletividade, os dois shoppings próximos à feira de artesãs reconfiguraram, de fato, o espaço público e a vizinhança, em termos simbólicos, econômicos e políticos, e o próprio comportamento daqueles que ali transitam ou habitam. Por exemplo, sua monumentalidade requereu distanciamento no entorno para sua visibilidade, que difere da situação gerada a partir das galerias comerciais próximas.

Porém, essa situação não intimidou as artesãs, que tiveram de reconhecê-la e desenvolver habilidades para ser vizinhas desses shoppings. A ocupação do espaço não é apenas material, mas também simbólica e fenomenológica. A territorialização se dá sob a forma de ocupação e disposição da feira, em seu posicionamento no espaço público social. Entrelaçam-se as dimensões econômica, política, cultural e simbólica. A feira não transgride a ordem definida naquele local, mas cria um enclave e insere-se no espaço social. A cada dia da feira, as artesãs precisam reconstruir fisicamente o espaço simbólico, passando a existir nesse lugar e assumindo uma posição diante dos outros, em especial de seus vizinhos.

Essa realidade difere da visão tradicional de uma comunidade de prática que se situa em um espaço próprio pré-existente, ou que se situa em um contexto e uma estrutura social de onde deriva aquilo que lhe serve de matriz ou fundamento. No caso estudado, temos o contrário. Essa comunidade precisa ter, entre as atividades de sua prática, aquelas dedicadas a trazer à existência seu lócus, seu espaço, seu território, concorrendo ou enfrentando as condições dominantes no espaço social. Aqui se diferenciam os conceitos de território - planejado, negociado, vivido.

\section{CONCLUSÃO}

A feira é um empreendimento coletivo, com centralidade no evento com local de comercialização, onde as artesãs expõem seus trabalhos.

Ela representa um espaço e tempo de conhecimento conjunto, um contexto comunitário e um ambiente de identidade daqueles que a compõem, no caso, em um sistema de economia solidária.

Há elementos para analisar o grupo empreendedor como uma comunidade de prática e a ação empreendedora coletiva como uma prática, sob o olhar da teoria social da aprendizagem.

Essas artesãs constituem, de fato, uma comunidade de prática. Compartilham um conjunto de problemas e interagem entre si sobre uma base contínua, criando produtos e desenvolvendo um entendimento tácito. Tal comunidade não se restringe ao momento e espaço da feira propriamente dita. A corporalização do empreendimento se estende a outras atividades em outros 
tempos e lugares, como uma construção coletiva dessas mulheres. Essa convivência e experiência hospedam e alimentam uma cultura que alcança suas famílias e seus lares, não se restringindo à feira.

Esta também é imaterial, pela forma como as atividades se organizam, ou seja, sua coordenação, sua direção, seu entrelaçamento. Não há um manual que possam consultar para obter orientações voltadas às suas ações e à sua existência. Nem existe um local pronto para que desempenhem seus papéis. De fato, parece que, como organização, apresenta-se mais ação do que estrutura. Há regras, quase todas não escritas, mas em menor número se compararmos com as organizações em geral. Ainda em relação a essa imaterialidade, destaca-se que existe uma capilaridade de atividades, tais como: a) compra da matéria-prima; b) pesquisa sobre como inovar no produto; c) pesquisa de fornecedores; d) produção; e) participação nas reuniões da feira; f) atividades da incubadora da feira; e g) participação nas formações de economia solidária - enfim, atividades que convergem para a prática aqui denominada feira.

A rigor, as feirantes se deparam com o enfretamento do poder, não só sob o aspecto legal (exigência de atenderem à regulamentação), mas sob as perspectivas econômica e cultural (a dominância do sistema capitalista e do consumismo vigente) e, ainda, sob a perspectiva espacial: a proximidade de dois grandes shoppings.

Contudo, elas conquistaram um lugar. Para a comunidade local e a vizinhança, a feira faz parte da paisagem e do ritmo dos acontecimentos locais. Há clientes que, antes de irem trabalhar, passam na barraca de alimentação para comprar seu lanche ou mesmo para ver a feira como um todo. Há outros atores que passam pela feira: são vendedores ambulantes, fiscais, moradores de rua, policiais, estudantes que querem conhecer a feira e funcionários do centro cultural do bairro. As feirantes acabam desenvolvendo uma convivência e um relacionamento com esses atores, aproximam-se e tentam, na medida do possível, auxiliá-los quando, por exemplo: a) dão café e pão para alguns moradores de rua; e b) fazem cestas com seus artesanatos para duas festividades específicas, a Páscoa e o Natal, que oferecem aos funcionários do centro cultural do bairro como forma de agradecimento pelo convívio durante todo o ano. São receptivas com estudantes ou qualquer pessoa que queira saber algo sobre a feira de economia solidária. Na comunidade de prática há uma temporalização, um calendário envolvendo a produção, que serve de precedente para a comercialização e territorialização.

Na percepção das artesãs, consoante o que foi observado e alcançado de outras formas na pesquisa, as relações estabelecidas por elas na territorialização combinam distanciamentos simbólicos e possibilidades de interação. A figura 2 procura representar esses elementos como um gradiente de posicionamentos na configuração desse território.

Figura 2

\section{Gradiente circular da territorialização como prática, interações e posicionamentos de grupo}

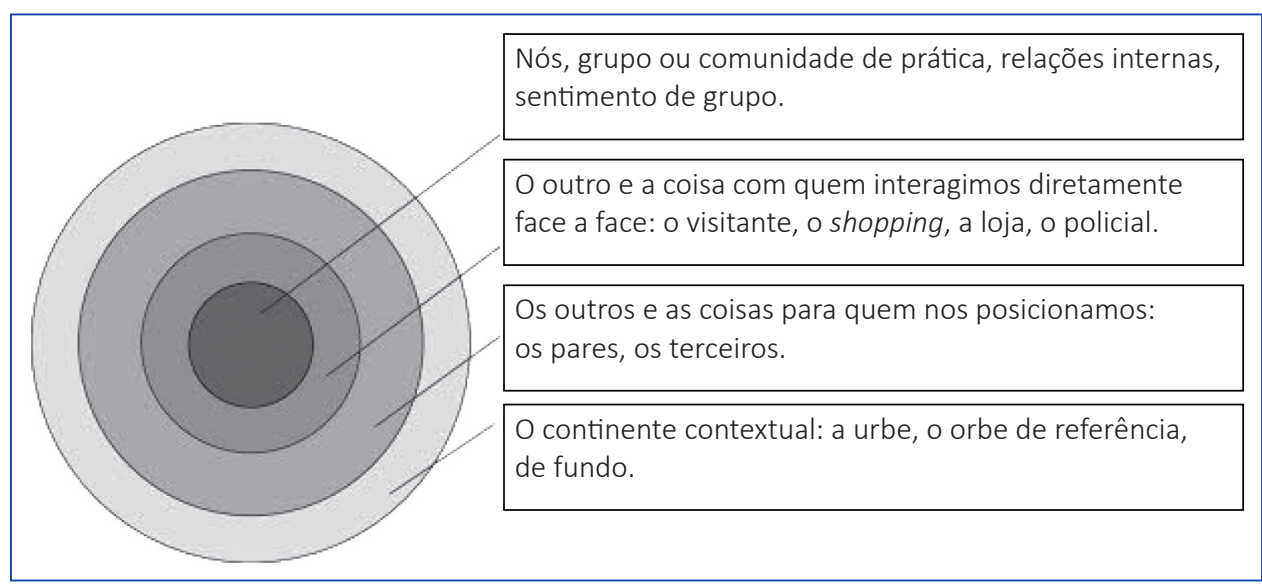

Fonte: Elaborada pelos autores.

As feirantes se apropriam do espaço público, constroem, simbolizam, significam e envolvem terceiros que passam por ali. Elas conseguem plasmar o próprio espaço, por isso têm um ritmo, uma proposta, um valor simbólico, que é essencialmente a combinação entre trabalho artesanal e economia solidária. Organizam as ações e as atividades, estabelecem ritmos e tempos. 
A observação e a análise viabilizaram a identificação das seguintes experiências e configurações de espaço e tempo, que acabam por desenhar os modos de participação:

1. O tempo e o espaço do transporte;

2. O tempo e o espaço da montagem;

3. O espaço e o tempo do evento;

4. O tempo e o espaço da sustentação e existência do evento público;

5. O tempo e o espaço do encontro e da prática comunitária;

6. O tempo e o espaço da reflexão e consolidação do conhecimento;

7. O tempo e o espaço do visitante da feira (kairós); e

8. Os tempos e os espaços da produção.

As atividades focadas na territorialização constituem prática fundamental para esse tipo de empreendimento e implicam aprendizagem consoante o modelo proposto pela teoria social da prática em grupo ou em comunidade. 0 quadro 4 procura sintetizar esses dados e conclusões, considerando como ponto de partida os eixos principais da teoria social da prática, tal como proposto por Wenger (2011, pp. 20-30).

\section{Quadro 4}

Elementos da territorialização como prática e aprendizagem

\begin{tabular}{|c|c|c|c|c|}
\hline $\begin{array}{l}\text { Eixos principais } \\
\text { da teoria social }\end{array}$ & $\begin{array}{l}\text { Implicações quanto } \\
\text { à aprendizagem } \\
\text { comunitária }\end{array}$ & Conteúdos de territorialização & $\begin{array}{l}\text { Significados a partir dos } \\
\text { dados analisados }\end{array}$ & $\begin{array}{l}\text { Exemplos: citações e } \\
\text { trechos das entrevistas }\end{array}$ \\
\hline Comunidade & $\begin{array}{l}\text { - Afiliação } \\
\text { - Estrutura social }\end{array}$ & $\begin{array}{l}\text { Posicionamento } \\
\text { (econômico, político, cultural } \\
\text { simbólico) em relação: } \\
\text { - Ao outro } \\
\text { - Aos pares } \\
\text { - Ao contexto }\end{array}$ & $\begin{array}{l}\text { - Relacionar-se com } \\
\text { - Interagir com } \\
\text { - Empreender }\end{array}$ & $\begin{array}{l}\text { "Você dá sentido à } \\
\text { nossa existência, ao } \\
\text { nosso trabalho, ao nosso } \\
\text { empreendimento." }\end{array}$ \\
\hline Prática & $\begin{array}{l}\text { - Como fazer } \\
\text { Coordenar espaços e } \\
\text { tempos }\end{array}$ & $\begin{array}{l}\text { - Capacidade dinâmica de autogestão } \\
\text { e de gestão das interações (também } \\
\text { implica aprendizagem) } \\
\text { - Fronteiras }\end{array}$ & $\begin{array}{l}\text { - Construir } \\
\text { - Negociar } \\
\text { - Ocupar } \\
\text { - Confrontar } \\
\text { - Seduzir } \\
\text { - Cooptar } \\
\text { - Contratar } \\
\text { - Montar a feira } \\
\text { - Produzir artesanato } \\
\text { - Agir artisticamente }\end{array}$ & $\begin{array}{l}\text { "Eles percebem que } \\
\text { somos simples e sem } \\
\text { recursos." } \\
\text { "Cada uma faz seu } \\
\text { artesanato, mas tudo } \\
\text { aqui é pensado junto. } \\
\text { Cada detalhe." }\end{array}$ \\
\hline Significado & - Experiência & $\begin{array}{l}\text { - Sentido do trabalho } \\
\text { - Contraste com estrutura e espaço } \\
\text { sociais } \\
\text { - Ideais } \\
\text { - Vivência e aprendizagem de grupo }\end{array}$ & $\begin{array}{l}\text { - Explicar para si e para o } \\
\text { outro o que faz, por quê } \\
\text { e para quê } \\
\text { - Compreender o outro } \\
\text { e os outros } \\
\text { - Perceber as diferenças }\end{array}$ & $\begin{array}{l}\text { "Este nosso trabalho, } \\
\text { minha amiga, é } \\
\text { economia popular e } \\
\text { solidária!" } \\
\text { "Eu vivo e ofereço a } \\
\text { essas pessoas uma nova } \\
\text { maneira de viver, uma } \\
\text { nova economia." }\end{array}$ \\
\hline Identidade & $\begin{array}{l}\text { - Devir } \\
\text { - Processo } \\
\text { - Fluxo }\end{array}$ & $\begin{array}{l}\text { - Sentido de grupo como sujeito e } \\
\text { conteúdo, com crescente domínio } \\
\text { - Sentido de membros do grupo como } \\
\text { sujeitos com crescente domínio }\end{array}$ & $\begin{array}{l}\text { - Identificar e resolver os } \\
\text { problemas } \\
\text { - Definir quem somos e } \\
\text { qual é nosso lugar }\end{array}$ & $\begin{array}{l}\text { "Nós conseguimos } \\
\text { resolver nossos desafios. } \\
\text { Matamos um leão a cada } \\
\text { dia e semana!" }\end{array}$ \\
\hline
\end{tabular}

Fonte: Elaborado pelos autores. 
Permitindo-nos discutir um pouco mais com os conceitos das obras de nosso referencial teórico, nesse caso, a territorialização não significa somente a criação de um espaço físico ou de um lugar naquele trecho do bairro. E ela não se completa no posicionamento do grupo na geografia local e naquela paisagem dominada por 2 grandes shopping centers.

A territorialização é um elemento essencial na reconstrução de suas identidades e na aprendizagem. A construção semanal da feira é a materialização do cenário e da dramatização, da participação e vivência dos elementos culturais e de seus sentimentos e significações. Nesse conjunto de ações, vistas como uma prática, os papéis e as identidades estão nelas se reconstruindo e se reconfirmando. Há um nexo vital entre territorialização e identidades, pois nelas, por meio da participação, vêm sendo definidas: a) a experiência negociada de quem são como grupo e como agentes sociais, daquilo que estão fazendo ali e para quê; b) sua trajetória de aprendizagem; c) seus compromissos e responsabilidades; e d) suas afiliações. Assim se dá pela consciência e pelos conhecimentos exercidos no cotidiano referentes ao modo como elas se tornam reais como "nós" - um grupo - para os outros e se coisificam, ao modo como elas recompilam, representam e comunicam sua história e suas ligações e afiliações - e seus elementos culturais e simbólicos - e, finalmente, ao modo como cultivam sua existência política - por meio dos atos de escolha, de propósito, de posicionamento, de negociação, de futuro.

A identidade não é explicada somente pela natureza ocupacional de seu fazer, por ser artesãs. As observações e os dados apontam que a identidade está estreitamente ligada aos valores e aos significados de seus conhecimentos e suas interpretações a respeito do que é economia popular e daquilo que é economia solidária - tudo isso em face de estarem naquele território diante da comunidade - e as feirantes poderiam ser vistas como coatoras ou espectadoras.

Essa simbólica do artesanato corresponde às suas interpretações e constitui atos políticos. As feirantes têm consciência de que outras concorrem no espaço social, com divergentes valorações da produção individualizada, daquilo que é feito a mão.

Entretanto, seus artesanatos e a produção da feira fazem parte de sua trajetória de reflexão, de experiência, de aprendizagem. Por meio dessas ações de produção e territorialização artesanais, elas aprendem e negociam significados sociais e culturais, exercem alteridade e mantêm consciência de si como grupo.

\section{CONSIDERAÇÕES FINAIS}

Este estudo investigou como o mapeamento dos elementos espaço-temporais, sob uma perspectiva da aprendizagem situada, oferece novas luzes sobre o empreendimento em grupo como uma prática e sobre os conhecimentos compartilhados entre e por meio de comunidades organizacionais. E possibilita compreender, ainda, os processos da construção de identidades e das relações de poder ínsitas nas formas de participação e de aprendizagem em grupo.

Assumimos a noção de que espaço e tempo são constituintes das práticas sociais, bem como são constituídos por elas e pelas relações sociais. A forma como o grupo (comunidade) tem de posicionar-se no espaço social e interagir com os elementos e agentes externos para construir seu lócus é composta por um conjunto de atividades que dialoga com o contexto social e histórico da prática. Essas atividades constituem prática de posicionamento e territorialização no espaço social (o que difere da visão de que o contexto facilita e dificulta unilateralmente a aprendizagem e o compartilhamento).

A habilidade para construir a ordem espaço-temporal é uma forma de poder social. No caso, ela se revelou um desafio para o empreendimento em grupo e o conteúdo de aprendizagem situada e em comunidade.

Mostra-se difícil para as artesãs modificarem as condições espaciais e temporais de seu trabalho, mas tais condições caracterizam limitações e oportunidades de aprendizagem em grupo. Os encontros presenciais se dão na feira propriamente dita, mas quando se encontram em suas residências, realizando atividades de produção, elas trabalham em grupo a distância. 
A feira continua sendo o principal momento e lugar em que elas mantêm e reforçam suas identidades (em nível individual e coletivo), o senso de pertencimento ao seu grupo (comunidade) e de domínio da sua prática, além de compartilharem um sentido em suas atividades conjuntas.

Tal quadro de atividades e de organizing em grupo demonstra como o espaço e tempo nele configurados influenciam os modos de participação e apresentam elementos essenciais da aprendizagem e do domínio dessas mulheres em seu empreendimento e em suas relações.

Espera-se ter apontado neste artigo a possibilidade de diálogo entre o conceito de comunidade de prática e de ação empreendedora em grupo e os conceitos de espaço social e de territorialização, aventando que se possa investigar em maior profundidade as condições espaço-temporais e suas implicações quanto à aprendizagem.

\section{AGRADECIMENTOS}

Gostaríamos de prestar agradecimento à Universidade Positivo, pela bolsa do Programa Nacional de Pós- Doutorado/CAPES PNPD conforme Edital N. 005/2016 - PMDA. 


\section{REFERÊNCIAS}

Alves, C., Farias, G., \& Pereira, H. G. (2018). Cotidiano e identificação: o ser trabalhador pipoqueiro belo-horizontino. In Anais do 42ㅇ Encontro da Associação Nacional dos Programas de Pós-Graduação em Administração, Maringá, PR.

Bachelard, G. (1978). A filosofia do não; Novo espírito científico: a poética do espaço (Coleção Os Pensadores). São Paulo, SP: Abril Cultural.

Bourdieu, P. (1997). Efeitos do lugar. In P. Bourdieu (Org.), Miséria do mundo (pp. 159-166). Petrópolis, RJ: Vozes.

Bourdieu, P. (2013). Espaço físico, espaço social e espaço físico apropriado. Estudos Avançados, 27(79), 133-144.

Brown, J. S., \& Duguid, P. (1991). Organizational learning and communities of practice: toward a unified view of working, learning, and innovation. Organization Science, 2(1), 40-57.

Carrieri, A., Pereira, H. G., \& Correia, G. F. A. (2018). A pipoca e seu território nos arranjos organizativos de trabalhadores ambulantes belo-horizontinos. In Anais do 42 Encontro da Associação Nacional dos Programas de Pós-Graduação em Administração, Maringá, PR.

Certeau, M. (2014). A invenção do cotidiano. Petrópolis, RJ: Vozes.

Chiesa, C. D., Gois, P. H., De Luca, G. \& Cavedon, N. R. (2015). Tramando arames, pedras e fios: espaço e estigma no trabalho de um artista. Ciências Sociais Unisinos, 51(1), 32-41.

Davel, E., Cavedon, N. R., \& Fischer, T. (2012). A vitalidade artesanal da gestão contemporânea. Revista Interdisciplinar de Gestão Social, 1(3), 11-19.

Fahy, K. M., Easterby-Smith, M., \& Lervik, J. E. (2014). The power of spatial and temporal orderings in organizational learning. Management Learning, 45(2), 123-144.

Ferrarini, N. L., Camargo, D., \& Bulgacov, Y. L. M. (2014). Comunidades de práticas sociais e o debate sobre a formação do psicólogo. International Journal of developmental and educational Psichology INFAD, 2(1), 299-306.

Ferreira, T. B., Helal, D. H., \& Paiva, K. C. M. (2016). Artesanato, aprendizagem social e comunidade de prática: um estudo com rendeiras em Alcaçuz (RN). Revista Brasileira de Gestão e Desenvolvimento Regional, 12(1), 33-61.

Gherardi, S. (2012). How to conduct a practice-based study: problems and methods. Cheltenham, UK: Edward Elgar.

Giddens, A. (1985). Time, space and regionalisation. In D. Gregory, \& J. Urry (Ed.), Social relations and spatial structures (critical human geography) (pp. 265-295). Basingstoke, UK: Palgrave.

Giddens, A. (2003). A constituição da sociedade. São Paulo, SP: Martins Fontes.

Gouvêa, M. T. A., Paranhos, C., \& Motta, C. L. R. (2008). Promovendo o aprendizado organizacional por meio das comunidades de prática. Boletim Técnico do Senac, 34(3), 49-62.

Gropp, B. M. C. (2005). Uma abordagem etnográfica em comunidades de prática (Dissertação de Mestrado). Pontifícia Universidade Católica de São Paulo, São Paulo, SP.
Gropp, B. M. C. (2007). De cascão a lagartixa: uma abordagem etnográfica de comunidades de prática em aprendizagem organizacional. In J. A. Valente, K. Mazzone, \& M. C. Baranauskas (Org.), Aprendizagem na era das tecnologias digitais (v. 30235, pp. 203-222). São Paulo, SP: Cortez.

Gropp, B. M. C., \& Tavares, M. G. P. (2007). Comunidade de prática: gestão de conhecimento nas empresas. São Paulo, SP: Trevisan.

Haesbaert, R. (2015). O mito da desterritorialização. Rio de Janeiro, RJ: Bertrand Brasil.

Hagerstrand, T. (1975). Space, time and human conditions. In A. Karlqvist, L. Lundqvist, \& F. Snickars (Eds.), Dynamic allocation of urban space (pp. 3-14). Lexington, MA: Lexington.

Harvey, D. (2017). Condição pós-moderna. São Paulo, SP: Loyola.

Humes, L. L., \& Reinhard, N. (2006). A adoção do software livre na Universidade de São Paulo. RAUSP Management Journal, 41(3), 14-39.

Josselson, R. (2011). Narrative research: constructing, deconstructing and reconstructing story. In F. J. Wertz, K. Charmaz, L. M. McMullen, R. Josselson, R. Anderson, \& E. McSpadden (Org.), Five ways of doing qualitative analysis (pp. 224-242). New York, NY: Guilford.

Jovchelovitch, S., \& Bauer, M. W. (2002). Entrevista narrativa. In M. W. Bauer, \& G. Gaskell (Eds.), Pesquisa qualitativa com texto, imagem e som: um manual prático (pp. 90-113). Petrópolis, RJ: Vozes.

Lave, J. (2011). Apprenticeship in critical ethnographic practice. Chicago, IL: University of Chicago Press.

Lave, J., \& Wenger, E. (1991). Situated learning: legitimate peripheral participation. Cambridge, UK: Cambridge University Press.

Lefebvre, H. (1974). La production de l'espace. Paris, France: Anthropos.

Lengler, J. F. B., \& Cavedon, N. R. (2018). Do "templo do consumo" à representação mitológica: um olhar etnográfico desconstrutivo sobre os ritos no shopping center. In Anais do 42을 Encontro da Associação Nacional dos Programas de Pós-Graduação em Administração, Maringá, PR.

Lervik, J. E., Fahy, K. M., \& Eastertby-Smith, M. (2010). Temporal dynamics of situated learning in organizations. Management Learning, 41(3), 285-301.

Mendes, L. (2011). As culturas organizacionais territorializadas na atividade de camelô em Três Lagoas (Tese de Doutorado). Universidade Federal do Rio Grande do Sul, Porto Alegre, RS.

Mendes, L., \& Cavedon, N. R. (2013). As culturas organizacionais territorializadas. Revista de Ciências da Administração, 15(35), 108-123.

Mendes, L., \& Cavedon, N. R. (2014). O mercado de camelôs e as contribuições ao desenvolvimento local de uma cidade. Interações, 15(2), 341-352.

Mendes, L., \& Cavedon, N. R. (2015). Território como ordem e caos: relação de poder entre camelôs, poder público e comerciantes. BASE: Revista de Administração e Contabilidade da UNISINOS, 12(1), 15-26.

Mendes, L., \& Urbina, L. M. S. (2015). Análise sobre a produção acadêmica brasileira em comunidades de prática. Revista de Administração Contemporânea, 19(3), 305-327. 
Nicolini, D. (2013). Practice theory, work \& organization: an introduction. Oxford, UK: Oxford University Press.

Nicolini, D., Scarbrough, H., \& Gracheva, J. (2015). Communities of practice and situated learning in healthcare. In E. Ferlie, K. Montgomery, \& A. R. Pedersen (Ed.), Oxford handbook of health care management (pp. 255-278). Oxford, UK: Oxford University Press.

Pereira, D. C., \& Carrieri, A. P. (2005). Movimentos de desterritorialização e reterritorilização na transformação das organizações. Revista de Administração de Empresas, 4(1), 13-43.

Saquet, M. A. (2015). Abordagens e concepções de território. São Paulo, SP: Outras Expressões.

Schultze, F. (2010). Pesquisa biográfica e entrevista narrativa. In V. Weller, \& N. Pfaff (Org.), Metodologias da pesquisa qualitativa em educação: teoria e prática (pp. 211-222). Petrópolis, RJ: Vozes.

Stoddard, R. H. (2010). Field techniques and research methods in geography. Dubuque, IA: KendalUHunt.

Van-Maanen, J. (2009). A song for my supper: more tales of the field. Organizational Research Methods, 13(1), 240-255.

Van-Maanen, J., \& Barley, S. R. (1982). Occupational communities: culture and control in organizations. In B. Staw, \& L. Cummings (Ed.), Research in organizational behavior (v. 6, pp. 287-366). Greenwich, CT: JAI Press.

Van-Maanen, J., \& Kolb, D. (1982). The professional apprentice: observation on fieldwork roles in two organizational settings.
In S. B. Bacharach (Ed.), Research in organizational sociology (v. 3, pp. 1323-1382). Greenwich, CT: JAI Press.

Van-Manen, M. (2007). Phenomenology of practice. Phenomenology \& Practice, $1(1), 11-30$.

Vasconcelos, M. E. S. M., \& Domingues, F. F. (2018). Ser quem eu quiser na Liberdade: práticas de resistência na ocupação da Praça da Liberdade em Belo Horizonte-MG. In Anais do 42 Encontro da Associação Nacional dos Programas de Pós-Graduação em Administração, Maringá, PR.

Webster, L., \& Mertova, P. (2007). Using narrative inquiry as research method: an introduction to using critical event narrative analysis in research on learning and teaching. London, UK: Routledge.

Wenger, E. (1998). Communities of practice: learning, meaning, and identity. Cambridge, UK: Cambridge University Press.

Wenger, E. (2011). Comunidades de práctica: aprendizaje, significado e identidad. Buenos Aires, Argentina: Paidós.

Wenger, E., McDermott, R., \& Snyder, W. (2002). Cultivating communities of practice: a guide to managing knowledge. Boston, MA: Harvard Business School Press.

Zioli, E. G. O., Rodrigues, F. S., Gaffuri, E. L., \& Ichikawa, E. Y. (2018). As práticas cotidianas e os processos de territorialização de assentados no Município de Querência do Norte-RN. In Anais do 42 Encontro da Associação Nacional dos Programas de Pós-Graduação em Administração, Maringá, PR.

Ariane Latoski

ORCID: https://orcid.org/0000-0002-5208-6921

Pesquisadora associada pela Universidade Positivo no Programa de Doutorado em Administração; Pós Doutorado no Programa de Mestrado e Doutorado em Administração da Universidade Positivo. E-mail: ariane.latoski1@gmail.com

Eloy Eros da Silva Nogueira

ORCID: https://orcid.org/0000-0002-5234-496X

Professor e Pesquisador associado ao Grupo de Pesquisa Práticas, Subjetividade e Organizações pelo Programa de Mestrado e Doutorado em Administração da Universidade Positivo. E-mail: esn.ipe777@gmail.com 